\title{
Clients' and Therapists' Stories about Psychotherapy
}

Franklin W. Olin College of Engineering

\begin{abstract}
This article provides an overview of the emerging field of research on clients' stories about their experiences in psychotherapy. The theory of narrative identity suggests that individuals construct stories about their lives in order to provide the self with a sense of purpose and unity. Psychotherapy stories serve both psychological functions. Focusing on the theme of agency as a vehicle for operationalizing purpose and coherence as a way of operationalizing unity, this article will describe the existing scholarship connecting psychotherapy stories to clients' psychological well-being. Results from cross-sectional qualitative and quantitative studies as well as longitudinal research indicate a connection between the stories clients tell about therapy and their psychological well-being, both over the course of treatment and after it is over. In addition, a preliminary analysis of therapists' stories about their clients' treatment is presented. These analyses reveal that the way therapists recount a particular client's therapy does not impact the relationships between clients' narratives and their improvement. The article concludes with a discussion of how this body of scholarship might be fruitfully applied in the realm of clinical practice.
\end{abstract}

Keywords: narrative, psychotherapy, agency, coherence, identity

Stories are the currency of psychotherapy. Whatever the presenting problem, clients seek treatment because they want some kind of turning point; they want to unravel a predicament, to be absolved of wrongs, to heal an illness. They arrive for their first session with a collection of past chapters that explain to the therapist how they came to be in need of help. Treatment begins with this story, which informs how treatment will unfold. Over the course of the following sessionswhether they involve deep psychoanalytic excavation, pure experiential exposure therapy, or an eclectic conversationclients and their therapists wrestle with the myriad ways to understand clients' life experiences and to redirect them toward better times. In most instances, this revision process is implicit; very few approaches to therapy involve an explicit focus on editing clients' stories (though see Angus \& Greenberg, 2011, and White \& Epston, 1990, for examples of treatment that does explicitly embrace narrative). But regardless of the specific issues being addressed or the theoretical approach to treating them, understanding the psychotherapeutic endeavor in story terms makes sense. When it works, psychotherapy represents an experience of personal discontinuity, a turning point when a problem was addressed. It offers an opportunity for finding or remaking meaning. Both while treatment is unfolding and once it is over, clients are faced with the challenge of constructing a story about their experiences in therapy.
Given that psychotherapy is centrally concerned with stories, the ways clients narrate their experiences in treatment stand alongside the stories of their life experiences and are intimately intertwined with their progress. This is not a new idea. Jerome Frank (1961/1991) noted the centrality of clients' "therapeutic myth" in guiding treatment (p. 44). Frank framed the story of the treatment as a key element driving its success. He suggested that fostering this story provided the client with a foundation on which to build and maintain treatment gains. Donald Spence echoed this sentiment in his classic 1982 book, Narrative Truth and Historical Truth. Discussing the evolution of clients' stories about their lives, he wrote, "Once a given construction has acquired narrative truth, it becomes just as real as any other kind of truth; this new reality becomes a significant part of the psychoanalytic cure" (p. 31). Blending Frank's perspective with Spence's, make it clear that these same processes logically apply to the way clients narrate their treatment. Indeed, the stories clients construct about their therapy not only offer a window into the evolving personal meaning clients are composing, but may also impact the course

I would like to thank Ilana Walder-Biesanz and Luke H. Harmeling for their work coding the therapists' narratives discussed in this paper.

Correspondence concerning this article should be addressed to Jonathan M. Adler, Franklin W. Olin College of Engineering, Olin Way, MH 368, Needham, MA 02492. Email: jadler@olin.edu. 
of treatment itself. Despite the strong theoretical tradition speaking to this conclusion, very little empirical evidence has been identified to support it. In this article, I will present an overview of the research that connects clients' stories about their experiences in treatment to their psychological wellbeing. In addition, although there has been much less research on the topic, I will discuss work that has been done on therapists' narratives of treatment they have provided. This discussion will also feature preliminary analyses of some new data that speak to the role of therapists' psychotherapy stories.

Personality scientists have developed both strong theory and methods for investigating personal stories. One major contribution has been the theory of narrative identity, which suggests that every individual has an internalized and evolving story of the self that weaves together the self of today with the selves of the past and future (e.g., McAdams, 2001; McAdams \& Pals, 2006; McLean, Pasupathi, \& Pals, 2007; Singer, 2004). A wide body of empirical research has linked thematic and structural elements of personal narratives with psychological well-being, documenting the incremental validity of narratives in predicting psychological adjustment (e.g., Adler, 2012; Adler \& Hershfield, 2012; Adler, Kissel, \& McAdams, 2006; Bauer, McAdams, \& Sakaeda, 2005; Lodi-Smith, Geise, Roberts, \& Robins, 2009).

The theory of narrative identity suggests that our personal narratives serve two primary psychological functions. First, they crystallize the individual's sense of purpose; they explain what the individual believes his or her life is about (e.g., McAdams, 1996, 2001). Collecting individuals' own narratives is the best way to find out about the meanings they assign to events in their lives. Second, personal narratives imbue the self with unity across time and across situations (e.g., McAdams, 1996, 2001). While this smoothing of reality necessarily fails to accommodate the complexity of life, the seeming continuity of the self serves an integrating function, connecting the self of the past to the self of the present and the future. The psychotherapeutic experience poses a challenge to both the purpose and unity functions of narrative identity, and its course may be understood along each dimension. Indeed, like many of the most important personal narratives, clients' psychotherapy stories are fundamentally concerned with these two psychological functions.

\section{PURPOSE}

One of the key elements in evaluating the purpose function of narratives lies in examining the way the protagonist is portrayed. Every individual is both the narrator and the main character in his or her story (e.g., Josselson, 2004). This dual role was identified by William James when he described the difference between the $I$ and the $M e$ (1892/1963). James suggested that the process of developing a self (the $I$ ) ought to be considered as separate from the self-product that was produced (the $M e$; e.g., Blasi, 1988; McAdams, 1996). The constructive process of turning experience into self (the $I$ ) is ultimately responsible for distinguishing oneself from others, and the self that gets created (the $\mathrm{Me}$ ) has certain qualities that characterize it. Principal among these qualities is the extent to which the self is able to exert an influence over the individual's experience, versus being tossed around by external circumstances. This quality is captured by the construct of agency. James's $I$ has agentic properties, for the very act of creating a self involves the exertion of some influence over one's experience (e.g., Blasi, 1988; McAdams, 1996), but the $M e$ is created as a character in the personal narrative who also enjoys greater or lesser degrees of agency. It is important to note that agency is not the only way purpose is expressed in personal narratives, including stories about psychotherapy. Narratives might be organized around other themes as well, such as communion (e.g., McAdams, Hoffman, Mansfield, \& Day, 1996; Woike \& Polo, 2001).

Broadly construed, agency is concerned with the individual's autonomy, achievement, mastery, and ability to influence the course of his or her life (e.g., Bakan, 1966; Bandura, 2006; Deci \& Ryan, 2000; McAdams et al., 1996). ${ }^{1}$ Research on agency has provided support for the association between this theme in personal narratives and the narrator's psychological well-being (e.g., Adler, Chin, Kolisetty, \& Oltmanns, 2012; Helgeson, 1994; McAdams et al., 1996; Woike \& Polo, 2001). Nevertheless, psychotherapy may pose a threat to personal agency. The act of seeking help for one's psychological problems acknowledges an inability to ameliorate one's issues for oneself. Thus, when people begin psychotherapy, they typically do so with a diminished sense of their ability to satisfactorily influence their own circumstances. Empirical evidence supports this conclusion, grounded in studies wherein participants recounted themselves as being in a state of diminished agency at the start of treatment (Adler, 2012; Adler \& McAdams, 2007; Adler, Skalina, \& McAdams, 2008). While the act of seeking treatment may represent a blow to personal agency for some people and an increase in personal agency for others, the empirical evidence indicates that clients are significantly lower in agency prior to their first session of therapy than they are later in the course of treatment (Adler, 2012). Treatment brings an expert on board to work with the individual in addressing the problem, bringing with him or her a presumed competence. The work of therapy is conducted jointly between the therapist and the client in the service of the client's ultimate ability to manage his or her own challenges. Regardless of the theoretical approach to treatment or the specific presenting problems, the therapeutic process is therefore concerned with reinvigorating the client's sense of personal agency (e.g., Elliott \& James, 1989; McLeod, 1997; Omer \& Alon, 1997; Williams \& Levitt, 2007). As a result, constructing a narrative about the psychotherapeutic experience fundamentally must involve the client's struggles with his or her sense of agency.

Empirical research on clients' stories about their experiences in psychotherapy has provided support for the notion that agency is at the heart of the therapeutic endeavor and that 
enhancing agency is associated with positive psychological well-being. Qualitative cross-sectional research aimed at collecting rich retrospective accounts of clients' experiences in psychotherapy has repeatedly pointed to agency as a convergent theme among those clients whose treatment was successful (e.g., Adler \& McAdams, 2007; Gray, 2006; Nilsson, Svensson, Sandell, \& Clinton, 2007; Rhodes, Hill, Thompson, \& Elliott, 1994). For example, extrapolating from a set of 11 extensive case studies from people who self-identified as having recovered from a "mental breakdown" through treatment, Gray (2006) writes, "Deciding to get better and take charge of our recovery seems to be the single most important indicator of success in emerging from a breakdown" (p. 190). Quantitative cross-sectional research also provides support for the connection between clients' agency and their psychological well-being. Studies of individuals with significant psychopathology, such as schizophrenia and borderline personality disorder, have highlighted diminished agency (e.g., Adler et al., 2012; Lysaker, Lancaster, \& Lysaker, 2003). In addition, the results of a study my colleagues and I conducted indicated that the therapy stories constructed by individuals who had an optimal constellation of psychological well-being (i.e., high levels of subjective well-being plus high stages of ego development) were saturated with agentic language. This theme distinguished them from the therapy narratives of individuals with less-than-optimal psychological well-being (Adler et al., 2008).

Longitudinal research has also provided support for the conclusion that the theme of agency increases over the course of successful psychotherapy. In a longitudinal study I conducted (Adler, 2012), clients' narratives and their psychological well-being were assessed prior to the first session of psychotherapy and then again in between each session of treatment for the first 12 sessions. The narratives were coded for a variety of themes, including agency. Here is an excerpt from a narrative that was rated high in agency (as reported in Adler, 2012):

Being on my own is a scary place. At times, I feel like a little kid going somewhere for the first time - exciting, frustrating, wonderful, and scary all at once. These are a lot of changes in my life. I was feeling completely at their mercy, but now I see that I do have control. It's up to me to be able to stick with it and I will rise.

In this example, the narrator describes a transformation toward empowerment. The results of growth curve models indicated that clients' narratives showed increases in the theme of agency over the course of 12 sessions. Furthermore, these growth curve models revealed that increases in agency temporally preceded participants' clinical improvement. In other words, clients began to construct new private narratives that more prominently featured their own sense of agency and subsequently began to feel better. These results indicate that agency may play a significant role in the amelioration of poor mental health. In addition to this study, another longitudinal investigation of clients in a novel integrative treatment for depression found that the extent to which clients took an active role in processing their experience was associated with treatment outcome (Hayes, Beevers, Feldman, Laurenceau, \& Perlman, 2005), further suggesting that client agency plays an important role in psychotherapy progress.

Thus, a variety of perspectives drawn from theoretical work, qualitative and quantitative cross-sectional research, and longitudinal studies indicates that clients' sense of agency is associated with their psychological well-being both over the course of treatment and once psychotherapy has ended. These findings make it clear that the ways clients story their experiences in treatment are closely related to the purpose function of personal narratives.

\section{UNITY}

In addition to purpose, uniting the self across time and situations is a fundamental concern of personal narratives (e.g., McAdams, 1996, 2001). While much of personality is contextualized within situation and social roles, narrative identity serves to integrate the self across these situations. Lives unfold over time and yet the sense of self-continuity is important to most people. Bruner (1990) argued that narrative's "principal property is its inherent sequentiality" (p. 43). According to Bruner, diachronic integration is not simply a criterion by which narratives may be evaluated; it is a definitional standard for the form. Far from a simple linguistic phenomenon, constructing stories serves a "binding" function that holds together a sequence of moments, focused on preventing "the utter dispersion of experience, its evaporation into nothingness" (Freeman, 2010, p. 171). Indeed, we need narratives to hold on to our lives.

If agency serves as a key vehicle for operationalizing and assessing the purpose function of narrative identity, coherence offers a method for examining its unity function. When applied to personal narratives, coherence is justifiably more complex than the simple, logical, chronological sequencing of events. Temporal coherence is no doubt a pillar of narrative coherence, and successful narratives must make plain their chronology (e.g., Habermas \& Bluck, 2000). Yet coherent narratives do more than just unfold in a logical sequence. Habermas and Bluck (2000) assert that narrative coherence is also concerned with the extent to which the story makes causal connections between events in the plot and also between the story scenes and the narrator's sense of self. This causal coherence explains apparent discontinuities in the story and also explains how the person's life experiences impacted his or her developing identity (e.g., Pals, 2006). In addition, successful narratives contain thematic coherence, including often implicit repeated story elements that, when assessed holistically, reveal something about the main character or the narrator (Habermas \& Bluck, 2000). Finally, narratives must also adhere to a cultural concept of biography, a corresponding to societal templates for 
how stories ought to unfold and may be understood (Habermas \& Bluck, 2000; Hammack, 2008). Taken together, these four types of coherence deeply tap the ways in which narratives provide a unifying function for the self.

Just as psychotherapy presents a challenge to agency, psychosocial treatment and the events that led up to it also complicate the individual's sense of coherence. Psychopathology and other problems in life that precede psychotherapy can be understood as discontinuities in narrative identity. When an individual experiences the onset of a psychological problem or a significant negative life event, he or she is faced with the challenge of incorporating that experience into his or her unfolding sense of self. Such episodes can disrupt all four dimensions of narrative coherence. For example, being unexpectedly fired from one's job may interrupt one's sense of causal coherence by leaving the individual struggling to find a reason for the dismissal; the emergence of a psychotic break may be understood as a deviation from the cultural concept of biography, as typical life stories do not include such episodes. Likewise, when someone decides to seek treatment for a long-standing, seemingly dispositional, problem, he or she is implicitly expressing a discomfort with the thematic coherence that has characterized his or her life. There has been much theoretical interest in describing the ways in which psychopathology can be understood in terms of narrative coherence (e.g., Dimaggio, 2006; Jørgensen, 2010; Lysaker \& Lysaker, 2006; Semerari, Carcione, Dimaggio, Nicolo, \& Procacci, 2007; Wilkinson-Ryan \& Westen, 2000). The thrust of this theoretical work has been to suggest that a failure to satisfactorily integrate the disparate aspects of one's experience into a coherent story serves as evidence of, or perhaps even the cause of, psychological problems. It is worth noting that there have been several convincing critiques of the perspective that coherence is the basis by which narratives should be evaluated (e.g., Gergen, 2000; Hermans, Kempen, \& van Loon, 1992; Hyvärinen, Hydén, Saarenheimo, \& Tamboukou, 2010; Singer, 1996). Yet even within many of the critiques of coherence as a foundational element of narratives runs an implicit suggestion that coherence and psychological well-being are connected (Freeman, 2010).

Empirical research on the coherence of psychotherapy clients' narratives has provided a solid foundation for the connection between coherence and psychological well-being. Significant attention has been paid to disruptions in narrative coherence among people with schizophrenia (e.g., Dimaggio, 2006; Gruber \& Kring, 2008; Lysaker \& Lysaker, 2006; Roe, 2001). For example, Gruber and Kring (2008) found that the stories about emotional events told by people with schizophrenia were significantly different in their temporal and thematic coherence than those from a group of control participants. They describe the narratives of people with schizophrenia as having less clear meaning, being less appropriately suited to the prompt, and being less linear than those of healthy control participants, among other deficits. Gruber and Kring (2008) write, "Schizophrenia patients had a difficult time recounting their emotional life stories in a manner that yielded a clear sequence of events, including what came before the event and what happened afterwards" (p. 531). Problems with narrative coherence have been observed in other samples with significant psychopathology, such as borderline personality disorder (Adler et al., 2012), as well as in samples with generally low psychological well-being (e.g., Baerger \& McAdams, 1999). Psychotherapy has often been construed as a process that is fundamentally concerned with enhancing the client's narrative coherence (e.g., Dimaggio, Salvatore, Azzara, \& Catania, 2003; Neimeyer, Herrero, \& Botella, 2006; Salvatore et al., 2006; Singer \& Rexhaj, 2006). Cross-sectional retrospective research has demonstrated that clients in good mental health recount their experiences in psychotherapy with a greater degree of narrative coherence than those who are worse off after treatment (Adler et al., 2008).

Longitudinal research has also provided evidence that psychotherapy clients' narratives increase in coherence over the course of treatment. In one study, Lysaker and colleagues found that the narratives of people with schizophrenia who had relatively intact neurocognitive abilities increased in their overall coherence after five months in a vocational rehabilitation program (Lysaker, Davis, Hunter, Nees, \& Wickett, 2005). In another study, van Minnen and colleagues found that the narratives of people with posttraumatic stress disorder decreased in disorganization after nine weekly sessions of prolonged exposure treatment and that the participants who experienced the greatest reduction in symptoms also showed greater increases in their narrative organization (van Minnen, Wessel, Dijkstra, \& Roelofs, 2002). In the longitudinal study of clients' narratives that I conducted, described above (Adler, 2012), no reliable changes in narrative coherence were observed over the course of treatment. However, in a reanalysis of the data from that study (Adler, Harmeling, \& WalderBiesanz, 2013), elevated levels of coherence were observed in the narrative collected at the assessment point immediately preceding rapid and substantial improvements in clients' psychological well-being. In other words, while narrative coherence did not show a reliable trajectory of change over the early phase of treatment, higher levels of coherence did precede substantial improvements in clients' mental health. The pattern of findings across these three longitudinal studies indicates that the coherence of clients' narratives is associated with their psychological well-being.

\section{CLIENTS' NARRATIVES OF PSYCHOTHERAPY: SUMMARY}

The stories clients tell about their experiences in psychotherapy tap into the two primary functions of personal narratives: they capture the sense of purpose the individual has constructed, making clear how the client-as-main-character interacts with his or her world, and they also serve to unite the client's identity across the potentially disruptive experience of 
seeking help for a problem. The narrative theme of agency and structural element of coherence offer opportunities to operationalize these two psychological functions of narratives, and each has an emerging tradition of scholarship demonstrating its connection to clients' psychological well-being.

Specifically, both agency and coherence have been associated with psychological well-being in clients' therapy narratives when assessed using cross-sectional qualitative and quantitative approaches and in longitudinal studies. The results from this developing field of research highlights the importance of clients' stories about their experiences in therapy, both during the course of treatment and after it is over.

It is worth noting that therapy stories are not the only important narratives worthy of investigation. Certainly clients' stories about their life experiences are also likely to show significant evolution over the course of psychotherapy, and these narrative changes are also likely to be associated with clinical improvement (see Hayes et al., 2005, for a nice example). However, at least since Frank (1961/1991), the therapy story itself has been regarded as special. Psychotherapy is an unusual experience in the life course, and clients need to develop a story about their treatment in order to hold on to the progress they have made. The therapy story may therefore serve as the foundation for the maintenance of treatment gains.

It is also worth noting that psychological well-being, as it has been discussed in this article, is not the only way of assessing the success of psychotherapy. Certainly hedonic conceptions of psychological well-being dominate the psychotherapy outcome literature, but other outcomes such as wisdom, ego development, personal growth, acceptance of loss, and connection to others may also be important products of psychotherapy (e.g., King, 2001).

\section{WHAT ABOUT THERAPISTS' NARRATIVES?}

It seems clear that clients' narratives about psychotherapy are intimately intertwined with their psychological well-being. Yet in any episode of individual psychotherapy, there is another story to be told about the treatment: the therapist's story. As the lone other person in the therapy room, the therapist also constructs narratives about the way treatment unfolded and why it was or was not successful. It certainly seems possible that therapists' narratives might inform their outlook and behaviors and therefore also be associated with clients' progress. Whose story is more important in influencing clients' improvement?

In 1974, Irving Yalom published a book titled Every Day Gets a Little Closer: A Twice-Told Therapy, in which he and one of his clients, Ginny Elkan, kept diaries about their work together. The book highlighted the connections and disconnections between these two perspectives. Since then, a limited amount of empirical research has directly investigated therapists' and clients' stories. This body of scholarship has tended to emphasize the differences between the reconstructions, what Mintz, Auerbach, Luborsky, and Johnson (1973) labeled the "Rashamon phenomenon" after the famous Kurosawa film. For example, in a study looking at recently completed psychotherapy, Llewelyn (1988) demonstrated that therapists tended to point to clients' development of insight as the most helpful component of treatment, whereas clients tended to point to discussions about problem solving as the most helpful component of treatment. She found that treatment outcome was not associated with congruence between the perspectives, but instead, outcome was associated with the extent to which each participant, therapist or client, felt the key ingredient (either the development of insight or problem solving) had been present. Disconnections like these have been further identified in subsequent research (e.g., Levander \& Werbart, 2003; Lietaer, 1992; Milbrath et al., 1995; Tyron, Blackwell, \& Hammel, 2007; Wark, 1994; Werbart \& Levander, 2005, 2006, 2011).

Yalom and Elkan's (1974) book presented two unfolding narratives in a rich, qualitative manner. Subsequent qualitative work has also focused on the additional utility of collecting therapists' narratives (e.g., Geller, 2005; Levander \& Werbart, 2003; Orlinsky \& Howard, 1977; Rober, Elliott, Buysse, Loots, \& De Corte, 2008; Werbart \& Levander, 2005, 2006, 2011), but most of the quantitative work on this topic has used other methods, such as questionnaires, for assessing therapist and client perspectives (e.g., Lang, Davidson, Bailey, \& Levine, 1999; Manthei, 2007; Rosenheck \& Lam, 1997). These methods do allow for the simultaneous assessment of therapists' and clients' perspectives, but they lose the depth and nuance available in narratives. As a part of the longitudinal study of clients' narratives over the course of psychotherapy that I conducted and discussed above (Adler, 2012), therapists were also asked to write short narratives after their clients completed participation in the study, reflecting on how the treatment unfolded and why it was or was not successful. These short narratives offer an opportunity to quantitatively examine the relationship between therapists' narratives of treatment and the evolution of clients' own narratives and psychological well-being. I am not aware of another study that has combined the thematic coding of private narratives collected from both therapists and clients and growth curve modeling techniques. Although the longitudinal study was not specifically designed to assess therapists' narratives, the data they provided offer a very preliminary window into the associations between therapists' and clients' narratives and treatment progress.

The specific details of the study's methodology can be found in the primary publication on this dataset (Adler, 2012); briefly, 47 adults seeking individual outpatient psychotherapy wrote private narratives prior to their first session of treatment and again in between every session for up to 12 sessions. They also completed a standardized measure of psychological wellbeing (the Individual Problems and Strengths subscale of the Systemic Therapy Inventory of Change; Pinsof et al., 2009). 
Thirty-two therapists worked with the clients who were enrolled in the study (some therapists worked with more than one client in the study; demographic characteristics of the therapist sample are reported in Adler, 2012). After the 12th session of treatment, therapists were asked to respond to several short prompts: "Please describe the problem for which this client sought treatment," "How much has this client changed since the beginning of treatment," "How much progress did this client make on his/her initial presenting problem(s)," and "Why has therapy worked/not worked for this client?" While these prompts do not explicitly call upon the therapist to craft a single overarching narrative of treatment, when aggregated together they do produce a story-like structure, gleaning the therapist's take on the beginning, middle, and end of the client's experience. In this way, they echo the series of prompts I developed and used in two previous studies of clients' retrospective therapy narratives (Adler \& McAdams, 2007; Adler et al., 2008) that asked clients to discuss their problem, key moments from the treatment, and some resolution to and reflection on the experience.

As discussed above, agency and coherence represent two principal qualities of clients' therapy stories that are associated with outcome. It was not possible to successfully code therapists' narratives from this sample for coherence, given the choppy way in which the prompts were presented (again, the study was not specifically designed to answer this question). However, it was possible to code therapists' narratives for their own sense of agency and for their perspective on the client's agency. Two raters trained to high standards of interrater reliability used the same coding system for assessing agency that had been used to evaluate clients' narratives (Adler, 2012). Therapists' narratives were coded for (a) the extent to which they prominently featured the therapist's agency $(\mathrm{ICC}=0.80)$ and $(\mathrm{b})$ the extent to which they prominently featured the client's agency $(\mathrm{ICC}=0.83)$. (These raters were not the same raters as those who assisted in the assessment of clients' narratives.) Since these two dimensions were coded separately, it was possible for a given therapist narrative to include both themes (or neither of them). An example of a narrative that received a high score on therapist's agency is as follows:

Treatment worked very well because of [the client's] trust for me, which was initially very difficult for her (due to her history with her family). I think this was possible because I was competent about her problem and cared about her as a person. I think my using examples from my own life in the treatment also helped greatly.

In this example, the therapist cites her own competence and therapeutic techniques as the reason for the client's improvement. Thus, in this response it is the therapist's qualities that influenced treatment progress, revealing a high degree of therapist agency. In contrast, here is an example of a therapist's response that scored very high for client agency:
I think the therapy worked because [the client] generally did most of the homework. She also believed/understood the cognitive-behavioral therapy model and could see how the model was reflected in her own behaviors. She stated several times that using the techniques (challenging thoughts, breathing) were helpful. I think it also worked because she's rather driven and tough-minded, in my opinion.

In this example, the therapist portrays treatment's success as being due to the client's actions and disposition. Using the therapeutic techniques and doing the homework were active tools used by the client that are identified as the mechanisms of her improvement.

Therapists' reports of therapist agency and client agency were not significantly correlated with each other $(r=-.02$, $p=.88$ ). Neither report was associated with any therapist demographic variable, with the exception of therapist agency, which was significantly positively correlated with therapist age $(r=.34, p<.05)$. In addition, neither therapist report was significantly correlated with agency as it was coded in clients' narratives or with clients' psychological well-being at either the initial pretherapy assessment point or at the 12th assessment point, concurrent with therapists' report.

The primary analysis of this dataset employed multilevel modeling to assess the growth curve trajectories of clients' narratives and their psychological well-being (Adler, 2012). Some of the major findings from that study were as follows: (a) clients' psychological well-being improved over the course of treatment; (b) agency in clients' narratives was significantly positively associated with their psychological well-being; and (c) lagged growth curve models indicated that changes in agency in clients' narratives temporally preceded improvements in their psychological well-being, and not vice versa. These findings remained significant across a variety of therapist variables and client variables, including clients' personality traits and ego development. Having now coded therapists' responses for therapist agency and client agency, it was possible to return to the initial set of analyses and add these two variables at a second level in the models. In other words, it was possible to examine whether changes in clients' psychological well-being or their agency, as coded in clients' narratives, differed across clients whose therapists described their treatment as primarily concerned with the therapist's agency or with the client's agency. A series of multilevel models was constructed to assess each of the primary hypotheses tested and reported in Adler (2012) and summarized above.

Neither therapists' report of therapist agency nor their reports of clients' agency significantly impacted any of the growth curve models tested and reported in Adler (2012). Indeed, the associations between clients' own sense of agency and their subsequent clinical improvement were observed regardless of whether their therapist reconstructed the story of the treatment as prominently featuring the therapist's agency or the client's agency. Adding therapists' perspectives to the 
models did not significantly impact any of the results identified in the longitudinal study.

Although the original study had not initially been designed to specifically assess the role of therapists' narratives, the results of this reanalysis present an incremental step in suggesting that clients' stories - not therapists' stories - are the potent ingredient in clinical improvement. While the majority of research on therapist variables has failed to yield strong associations between a wide variety of therapist characteristics and treatment outcomes (Beutler et al., 2004), little empirical attention has been paid to the potential influence of therapists' narratives of treatment. The results presented here offer preliminary evidence that clients' own narratives about their experiences in therapy are the key element in influencing their clinical improvement, not their therapists' narratives.

Of course, the data presented here do not allow for a nuanced interpretation of the null relationship observed between therapists' and clients' narratives. For example, it is possible that therapists conceived of their work in terms of the techniques that they used, whereas the client, having benefitted from these techniques, came to interpret treatment in terms of his or her enhanced agency that resulted from developing new strategies for managing his or her problem. If a subtle process like this were occurring, it might be explained as the client's unconscious internalization of the therapist. In this scenario, the therapist's and client's narratives would diverge on the theme of agency, but an observer might craft an overarching narrative of transactional and iterative agency (see Geller, 2005 , for an example of this scenario). ${ }^{2}$

Although the results of the investigation presented here produced null results, future research into the associations between therapists' and clients' narratives and clients' psychological well-being would benefit from looking further into the role of agency, as well as the structural coherence of the therapists' narratives, especially as they unfold over time. The study from which the therapist narratives were drawn for the analyses presented in this article did not include repeated collection of therapist narratives, so their unfolding trajectory could not be assessed. Any convergence and divergence of therapists' and clients' narratives over time could not be assessed here, and it is possible that certain patterns might yield significant results. In future research, it would also be fruitful to examine such dynamics in other treatment modalities, such as couple, family, or group therapy. It seems possible that multiple clients might develop a shared sense of collective agency that might or might not converge with each other's and their therapist's/ facilitator's individual stories and that such associations might be associated with treatment outcome.

\section{CONCLUSION AND IMPLICATIONS FOR CLINICAL PRACTICE}

The emerging field of research on clients' narratives about their experiences in psychotherapy, reviewed above, indicates that the ways clients construct stories about treatment are an important focus for researchers and practitioners alike. The story of the therapeutic episode is a prime candidate for incorporation into narrative identity. Indeed, people who have been in psychotherapy often spontaneously mention the experience when recounting their life stories, and when they do, they point to it as a key period of personal development (e.g., Lieblich, 2004). These narratives serve vital psychological functions, tapping into the individual's sense of purpose and unity, both when constructed during the course of treatment and after it is over. The few existing studies that have empirically tracked clients' stories about their experiences in therapy over the course of treatment have clearly demonstrated that certain elements of clients' narratives are associated with their therapeutic improvement. For example, the extent to which clients construe their experiences with a sense of personal agency has been found to increase over treatment and to precede increases in psychological well-being (Adler, 2012). Likewise, increases in the overall coherence of clients' narratives have been associated with positive treatment outcomes (e.g., Lysaker et al., 2005; van Minnen et al., 2002). Findings like these indicate that the stories clients construct about their experiences in therapy while it unfolds may have incremental validity in predicting treatment progress and outcome. Likewise, research on clients' retrospective accounts of psychotherapy suggests that these stories facilitate the maintenance of treatment gains, for different narrative themes in therapy stories have been differentially associated with psychological well-being. Both agency and coherence in these posttherapy accounts have also been found to discriminate between former clients with varying degrees of positive mental health following treatment (e.g., Adler et al., 2008).

The preliminary analysis of therapists' narratives included in this article serves to underscore the importance of clients' narratives to their psychological well-being. While no study has quantitatively examined the ways in which therapists' narratives unfold alongside their clients' stories in a fine-grained empirical way, the analyses presented above provide some initial evidence that it is really the clients' narratives that we should be interested in as researchers and practitioners. Indeed, neither therapists' conceptions of their own agency nor their conceptions of clients' agency were significantly associated with clients' mental health. In other words, although clients' narratives showed reliable shifts prior to their improvements, therapists' retrospective stories had no impact, at least based on the rudimentary assessment in this article. Just as clients naturally construct stories about their experiences in psychotherapy, their therapists no doubt also weave the work of treatment into narratives. But in the analyses presented here, these stories were irrelevant.

Taken together, the literature review and preliminary data analyses presented in this article lead to several implications for clinical practice. First and foremost is the conclusion that clients' stories about psychotherapy matter. Clients naturally craft these stories, and the way they do so is associated with 
their clinical progress and outcome. Although therapists also create stories about their clients' therapy, it is the clients' stories that are most strongly associated with clinical improvement. This means that case formulation would be fruitfully influenced by an understanding of clients' narratives. Such a perspective offers an index for assessing the extent to which the intended intervention strategies are being understood and adopted by clients. Kazdin (1980) asserted that although a treatment's efficacy may have been clearly demonstrated, it can fail with a given client if it is not properly understood or deemed unreasonable or unacceptable. This is especially important in light of the clearly demonstrated emphasis clients place on common factors when reflecting on their experiences in treatment (e.g., Adler, 2012; Gershefski, Arnkoff, Glass, \& Elkin, 1996; Levy, Glass, Arnkoff, \& Gershefski, 1996; Omer \& Alon, 1997; Shapiro, 1995). Yet narratives provide more than a simple index of whether clients comprehend their therapist's intentions. They also render examinable the ways in which clients internalize their experiences in treatment and incorporate this period of change into their evolving sense of self. The particular contours of a given client's therapy narrative may therefore hold the key to best understanding the depth at which a given intervention impacts the individual.

Second, the conclusions of this article indicate that therapists ought to cultivate a practice of asking clients about their therapy stories as part of the ongoing work of clinical assessment and progress tracking. While therapists operating from differing theoretical orientations will no doubt conceive of and approach their clients' narratives in different manners, staying attuned to clients' unfolding therapy narratives and eliciting them on occasion are simple interventions that any therapist might easily incorporate into his or her battery of techniques.

For example, cognitive-behavioral therapy encourages regular discussions of client progress, moments when the specific tools are put aside and clients' patterns of responses to self-report measures or other outcome instruments may be examined (e.g., Beck, 1995). These points of review offer an occasion for therapists to refine the intervention to accommodate the client's particular concerns or struggles, yet they also present an opportunity for cognitive-behavioral therapists to draw out clients' narratives about their work. Since cognitivebehavioral therapists are especially invested in the success of specific intervention strategies, such as graded exposure and cognitive restructuring techniques, these therapists might use these midtreatment review sessions to ask clients what they believe is making their work successful (or not). Based on the findings of the longitudinal study I conducted (Adler, 2012), listening for agentic language ("I am able to use the behavioral experiments effectively" or "I have mastered the thought record") can be interpreted as an indication of narrative progress. When clients offer treatment accounts that are lacking in agency ("I couldn't do it without the coping cards"), cognitive-behavioral therapists might use their battery of techniques for assessing the accuracy of clients' thoughts for reframing these statements in more agentic terms.
Psychodynamic therapists may be more used to prompting discussion of the therapeutic experience than cognitivebehavioral therapists, given their emphasis on transference as a mechanism of treatment (e.g., Luborsky \& Crits-Cristoph, 1990). Yet such interventions may overlook key narrative themes that pertain to client agency, at the expense of their ability to reveal unconscious processes. Nevertheless, a simple interpretation or direct question concerning the client's unfolding story of the treatment may point toward the role of agency in the client's implicit narrative ("I'm wondering if you have thoughts about why you are feeling differently?" or "Does that realization make you think differently about who you are, relative to who you have been?"). As in cognitive-behavioral treatment, psychodynamic therapists may work with clients to reframe non-agentic narratives ("I am only feeling better because of the strong supportive relationship I have with you") into more agentic stories ("I have been able to use my experience of our strong connection as a touchstone for getting what I need out of other relationships"). This technique ought to be easily accommodated by therapists of virtually any theoretical orientation.

In addition to eliciting clients' psychotherapy stories over the course of treatment, termination provides an especially important moment for therapists to ask clients about the way they will look back on treatment. These emerging retrospective narratives are important legacies of treatment, supporting the ongoing sense of purpose and unity of self once therapy has ended. Staying attuned to agency and coherence in these narratives may help therapists understand whether clients' stories are likely to continue to foster psychological well-being following termination.

Psychotherapy narratives offer a fruitful point of convergence for personality scientists, psychotherapy researchers, and practicing clinicians. Understanding the nature of change lies at the heart of each of these perspectives, and investigating how clients make meaning of their experiences in therapy through the development of personal narratives has the potential to mutually inform each approach. Just as personality research has tended to focus on dispositional traits, psychotherapy research has tended to focus on clients' symptoms in operationalizing change. Narratives offer a productive alternative in both domains, one that regards the individual as the expert on his or her own experience and privileges the voices of our participants and clients. As the work reviewed in this article demonstrates, the stories clients tell about their treatment present a vital avenue for understanding experiences of change.

\section{Notes}

1. There is some overlap between the theme of agency and the construct of self-efficacy (e.g., Bandura, 2006), yet assessing agency in personal narratives is not simply an interchangeable alternative to measuring self-efficacy via the traditional tool of questionnaires. The tradition of scholarship on self-efficacy has tended to emphasize the 
explicit ways individuals report their ability to achieve certain goals (e.g., Bandura, 2006). In contrast, assessing agency in personal narratives taps the implicit ways individuals actually go about making meaning of their lives in more or less agentic terms. In other words, agency "is self-efficacy in narrative action" (D. P. McAdams, personal communication, June 11, 2012); it captures the extent to which people organically understand the role of the main character (James's Me) in their own personal narratives. The contrast is not only a methodological one, but also, perhaps more importantly, a conceptual one.

2. I would like to thank Jefferson Singer and one of the anonymous reviewers of this article for proposing this potential interpretation.

\section{References}

Adler, J. M. (2012). Living into the story: Agency and coherence in a longitudinal study of narrative identity development and mental health over the course of psychotherapy. Journal of Personality and Social Psychology, 102, 367-389.

Adler, J. M., Chin, E. D., Kolisetty, A. P., \& Oltmanns, T. F. (2012). The distinguishing characteristics of narrative identity in adults with features of borderline personality disorder: An empirical investigation. Journal of Personality Disorders, 26, 498-512.

Adler, J. M., Harmeling, L., \& Walder-Biesanz, I. (2013). Sudden gains in psychotherapy clients' mental health and narrative meaning-making processes under routine clinical conditions. Manuscript under review.

Adler, J. M. \& Hershfield, H. E. (2012). Mixed emotional experience is associated with and precedes improvements in psychological well-being. PLOS ONE, 7(4), 1-10.

Adler, J. M., Kissel, E. C., \& McAdams, D. P. (2006). Emerging from the CAVE: Attributional style and the narrative study of identity in midlife adults. Cognitive Therapy and Research, 30, 39-51.

Adler, J. M., \& McAdams, D. P. (2007). The narrative reconstruction of psychotherapy. Narrative Inquiry, 17, 179-202.

Adler, J. M., Skalina, L. M., \& McAdams, D. P. (2008). The narrative reconstruction of psychotherapy and psychological health. Psychotherapy Research, 18, 719-734.

Angus, L. E., \& Greenberg, L. S. (2011). Working with narrative in emotion-focused therapy: Changing stories, healing lives. Washington, DC: American Psychological Association.

Baerger, D. R., \& McAdams, D. P. (1999). Life story coherence and its relation to psychological well-being. Narrative Inquiry, 9, 69-96.

Bakan, D. (1966). The duality of human existence. Boston: Beacon Press.

Bandura, A. (2006). Toward a psychology of human agency. Perspectives on Psychological Science, 1, 164-180.

Bauer, J. J., McAdams, D. P. \& Sakaeda, A. R. (2005). Interpreting the good life: Growth memories in the lives of mature, happy people. Journal of Personality and Social Psychology, 88, 203-217.

Beck, J. S. (1995). Cognitive therapy: Basics and beyond. New York: Guilford Press.

Beutler, L. E., Malik, M., Alimohamed, S., Harwood, T. M., Talebi, H., Noble, S., et al. (2004). Therapist variables. In M. J. Lambert (Ed.), Bergin and Garfield's handbook of psychotherapy (5th ed., pp. 227-306). New York: Wiley.
Blasi, A. (1988). Identity and the development of the self. In D. K. Lapsley \& F. C. Power (Eds.), Self, ego, and identity: Integrative approaches (pp. 226-242). New York: Springer-Verlag.

Bruner, J. (1990). Acts of meaning. Cambridge, MA: Harvard University Press.

Deci, E. L., \& Ryan, R. M. (2000). The "what" and "why" of goal pursuits: Human needs and the self-determination of behavior. Psychological Inquiry, 11, 227-268.

Dimaggio, G. (2006). Disorganized narratives in clinical practice. Journal of Constructivist Psychology, 19, 103-108.

Dimaggio, G., Salvatore, G., Azzara, C., \& Catania, D. (2003). Rewriting self-narratives: The therapeutic process. Journal of Constructivist Psychology, 16, 155-181.

Elliott, R., \& James, E. (1989). Varieties of client experience in psychotherapy: An analysis of the literature. Clinical Psychology Review, 9, 443-467.

Frank, J. D. (1961/1991). Persuasion and healing: A comparative study of psychotherapy. Oxford: Johns Hopkins University Press.

Freeman, M. (2010). "Even amidst": Rethinking narrative coherence. In M. Hyvärinen, L. C. Hydén, M. Saarenheimo, \& M. Tamboukou (Eds.), Beyond narrative coherence (pp. 167-186). Philadelphia: Johns Benjamins.

Geller, J. D. (2005). Boundaries and interpretation in the psychotherapy of psychotherapists: Clinical and research perspectives. In J. D. Geller, J. C. Norcross, \& D. E. Orlinsky (Eds.), The psychotherapist's own psychotherapy: Patient and clinician perspectives (pp. 379-404). New York: Oxford University Press.

Gergen, K. J. (2000). The saturated self: Dilemmas of identity in contemporary life. New York: Basic Books.

Gershefski, J. J., Arnkoff, D. B., Glass, C. R., \& Elkin, I. (1996). Clients' perceptions of treatment for depression: I. Helpful aspects. Psychotherapy Research, 6, 233-247.

Gray, P. (2006). The madness of our lives: Experiences of mental breakdown and recovery. London: Jessica Kingsleys.

Gruber, J., \& Kring, A. M. (2008). Narrating emotional events in schizophrenia. Journal of Abnormal Psychology, 117, 520-533.

Habermas, T., \& Bluck, S. (2000). Getting a life: The emergence of the life story in adolescence. Psychological Bulletin, 126, 748769.

Hammack, P. L. (2008). Narrative and the cultural psychology of identity. Personality and Social Psychology Review, 12, 222-247.

Hayes, A. M., Beevers, C. G., Feldman, G. C., Laurenceau, J.-P., \& Perlman, C. (2005). Avoidance and processing as predictors of symptom change and positive growth in an integrative therapy for depression. International Journal of Behavioral Medicine, 12 , 111-122.

Helgeson, V. S. (1994). Relation of agency and communion to wellbeing: Evidence and potential explanations. Psychological Bulletin, 116, 412-428.

Hermans, H. J. M., Kempen, H. J. G., \& van Loon, R. J. P. (1992). The dialogical self: Beyond individualism and rationalism. American Psychologist, 47, 23-33.

Hyvärinen, M., Hydén, L. C., Saarenheimo, M., \& Tamboukou, M. (2010). Beyond narrative coherence. Philadelphia: Johns Benjamins. 
James, W. (1892/1963). Psychology. Greenwich, CT: Fawcett.

Jørgensen, C. R. (2010). Invited essay: Identity and borderline personality disorder. Journal of Personality Disorders, 24, 344 364.

Josselson, R. (2004). On becoming the narrator of one's own life. In A. Lieblich, D. P. McAdams, \& R. Josselson (Eds.), Healing plots: The narrative basis of psychotherapy (pp. 111-128). Washington, DC: American Psychological Association.

Kazdin, A. E. (1980). Acceptability of alternative treatments for deviant child behavior. Journal of Applied Behavioral Analysis, 13, 259-273.

King, L. A. (2001). The hard road to the good life: The happy, mature person. Journal of Humanistic Psychology, 41, 51-72.

Lang, M. A., Davidson, L., Bailey, P., \& Levine, M. S. (1999). Clinicians' and clients' perspectives on the impact of assertive community treatment. Psychiatric Services, 50, 1331-1340.

Levander, S., \& Werbart, A. (2003). Different views of a psychotic breakdown - Complimentary perspectives of a bewildering experience. Psychoanalytic Psychotherapy, 17, 163-174.

Levy, J. A., Glass, C. R., Arnkoff, D. B., \& Gershefski, J. J. (1996). Clients' perceptions of treatment for depression II: Problematic or hindering aspects. Psychotherapy Research, 6, 249-262.

Lieblich, A. (2004). The place of psychotherapy in the life stories of women in households without men. In A. M. Lieblich, D. P. McAdams, \& R. Josselson, (Eds.), Healing plots: The narrative basis of psychotherapy (pp. 171-188). Washington, DC: American Psychological Association.

Lietaer, G. (1992). Helping and hindering processes in clientcentered/experiential psychotherapy: A content analysis of client and therapist post-session perceptions. In S. G. Toukmanian \& D. L. Rennie (Eds.), Psychotherapy process research: Paradigmatic and narrative approaches (pp. 134-162). London: Sage.

Llewelyn, S. P. (1988). Psychological therapy as viewed by clients and therapists. British Journal of Clinical Psychology, 27, 223 237.

Lodi-Smith, J., Geise, A. C., Roberts, B. W., \& Robins, R. W. (2009). Narrating personality change. Journal of Personality and Social Psychology, 96, 679-689.

Luborsky, L., \& Crits-Cristoph, P. (1990). Understanding transference. New York: Basic Books.

Lysaker, P. H., Davis, L. W., Hunter, N. L., Nees, M. A., \& Wickett, A. (2005). Personal narratives in schizophrenia: Increases in coherence following five months of vocational rehabilitation. Psychiatric Rehabilitation Journal, 29, 66-68.

Lysaker, P. H., Lancaster, R. S., \& Lysaker, J. T. (2003). Narrative transformation as an outcome in the psychotherapy of schizophrenia. Psychology and Psychotherapy: Theory, Research and Practice, 76, 285-299.

Lysaker, P. H., \& Lysaker, J. T. (2006). A typology of narrative impoverishment in schizophrenia: Implications for understanding the processes of establishing and sustaining dialogue in individual psychotherapy. Counseling Psychology Quarterly, 19, 57-68.

Manthei, R. J. (1997). Client-counselor agreement on what happens in counseling. British Journal of Guidance and Counseling, 35, 261-281.
McAdams, D. P. (1996). Personality, modernity, and the storied self: A contemporary framework for studying persons. Psychological Inquiry, 7, 295-321.

McAdams, D. P. (2001). The psychology of life stories. Review of General Psychology, 5, 100-122.

McAdams, D. P., Hoffman, B. J., Mansfield, E. D., \& Day, R. (1996). Themes of agency and communion in significant autobiographical scenes. Journal of Personality, 64, 339-377.

McAdams, D. P., \& Pals, J. L. (2006). A new Big Five: Fundamental principles for an integrative science of personality. American Psychologist, 61, 204-217.

McLean, K. C., Pasupathi, M., \& Pals, J. L. (2007). Selves creating stories creating selves: A process model of self development. Personality and Social Psychological Review, 11, 262-278.

McLeod, J. (1997). Narrative and psychotherapy. New York: Sage.

Milbrath, C., Bauknight, R., Horowitz, M. J., Amaro, R., \& Sugahara, C. (1995). Sequential analysis of topics in psychotherapy discourse: A single-case study. Psychotherapy Research, 5, 199-217.

Mintz, J., Auerbach, A., Luborsky, L., \& Johnson, M. (1973). Patients', therapists', and observers' views of psychotherapy: A Rashamon experience or a reasonable consensus? British Journal of Medical Psychology, 46, 83-89.

Neimeyer, R. A., Herrero, O., \& Botella, L. (2006). Chaos to coherence: Psychotherapeutic integration of traumatic loss. Journal of Constructivist Psychology, 19, 127-145.

Nilsson, T., Svensson, M., Sandell, R., \& Clinton, D. (2007). Patients' experiences of change in cognitive-behavioral therapy and psychodynamic therapy: A quantitative comparative study. Psychotherapy Research, 17, 535-566.

Omer, H., \& Alon, N. (1997). Constructing therapeutic narratives. London: Jason Aronson.

Orlinsky, D. E., \& Howard, K. I. (1977). The therapist's experience of psychotherapy. In A. S. Gurman \& A. M. Razin (Eds.), Effective psychotherapy: A handbook of research (pp. 566-589). New York: Pergamon Press.

Pals, J. L. (2006). Narrative identity processing of difficult life experiences: Pathways of personality development and positive self-transformation in adulthood. Journal of Personality, 74, 1079-1110.

Pinsof, W. M., Zinbarg, R. E., Lebow, J. L., Knobloch-Fedders, L. M., Durbin, C. E., Chambers, A., et al. (2009). Laying the foundation for progress research in family, couple, and individual therapy: The development and psychometric features of the initial Systemic Therapy Inventory of Change. Psychotherapy Research, 19, $143-156$

Rhodes, R. H., Hill, C. E., Thompson, B. J., \& Elliott, R. (1994). Client retrospective recall of resolved and unresolved misunderstanding events. Journal of Counseling Psychology, 41, 473-483.

Rober, P., Elliott, R., Buysse, A., Loots, G., \& De Corte, K. (2008). What's on the therapist's mind? A grounded theory analysis of family therapist reflections during individual therapy sessions. Psychotherapy Research, 18, 48-57.

Roe, D. (2001). Progressing from patienthood to personhood across the multidimensional outcomes in schizophrenia and related disorders. Journal of Nervous and Mental Disease, 189, 691-699. 
Rosenheck, R., \& Lam, J. A. (1997). Homeless mentally ill clients' and providers' perceptions of service needs and clients' use of services. Psychiatric Services, 48, 381-386.

Salvatore, G., Conti, L., Fiore, D., Carcione, A., Dimaggio, G., \& Semerari, A. (2006). Disorganized narratives: Problems in treatment and therapist intervention hierarchy. Journal of Constructivist Psychology, 19, 191-207.

Semerari, A., Carcione, A., Dimaggio, G., Nicolo, G., \& Procacci, M. (2007). Understanding minds: Different functions and different disorders? The contribution of psychotherapy research. Psychotherapy Research, 17, 106-119.

Shapiro, D. A. (1995). Finding out how psychotherapies help people change. Psychotherapy Research, 5, 1-21.

Singer, J. A. (1996). To integrate or not to integrate: A dilemma for modern personality theory. Psychological Inquiry, 7, 367371.

Singer, J. A. (2004). Narrative identity and meaning-making across the lifespan: An introduction. Journal of Personality, 72, 437459.

Singer, J. A., \& Rexhaj, B. (2006). Narrative coherence and psychotherapy: A commentary. Journal of Constructivist Psychology, 19 209-217.

Spence, D. P. (1982). Narrative truth and historical truth: Meaning and interpretation in psychoanalysis. New York: W. W. Norton.

Tyron, G. S., Blackwell, S. C., \& Hammel, E. F. (2007). A metaanalytic examination of client-therapist perspectives of the working alliance. Psychotherapy Research, 17, 629-642. van Minnen, A., Wessel, I., Dijkstra, T., \& Roelofs, K. (2002). Changes in PTSD patients' narratives during prolonged exposure therapy: A replication and extension. Journal of Traumatic Stress, 15, 255-258.

Wark, L. (1994). Therapeutic change in couples' therapy: Critical change incidents perceived by therapists and clients. Contemporary Family Therapy: An International Journal, 16, 39-52.

Werbart, A., \& Levander, S. (2005). Understanding the incomprehensible: Private theories of first-episode psychotic patients and their therapists. Bulletin of the Menninger Clinic, 69, 103-136.

Werbart, A., \& Levander, S. (2006). Two sets of private theories in analysands and their analysts: Utopian versus attainable cures. Psychoanalytic Psychology, 23, 108-127.

Werbart, A., \& Levander, S. (2011). Vicissitudes of ideas of cure in analysands and their analysts: A longitudinal interview study. International Journal of Psychoanalysis, 92, 1455-1481.

White, M., \& Epston, D. (1990). Narrative means to therapeutic ends. New York: W. W. Norton.

Wilkinson-Ryan, T., \& Westen, D. (2000). Identity disturbance in borderline personality disorder: An empirical investigation. American Journal of Psychiatry, 157, 528-541.

Williams, D. C., \& Levitt, H. M. (2007). Principles for facilitating agency in psychotherapy. Psychotherapy Research, 17, 66-82.

Woike, B., \& Polo, M. (2001). Motive-related memories: Content, structure, and affect. Journal of Personality, 69, 391-415.

Yalom, I., \& Elkin, G. (1974). Every day gets a little closer: A twice-told therapy. New York: Basic Books. 